\title{
Self-Reported Snoring, Maternal Obesity and Neck Circumference as Risk Factors for Pregnancy-Induced Hypertension and Preeclampsia
}

\author{
Ahmet Ursavas $^{\mathrm{a}} \quad$ Mehmet Karadag $^{\mathrm{a}} \quad$ Nazan Nalcl $^{\mathrm{a}} \quad$ Ilker Ercan $^{\mathrm{b}}$ R. Oktay Gozu ${ }^{\mathrm{a}}$

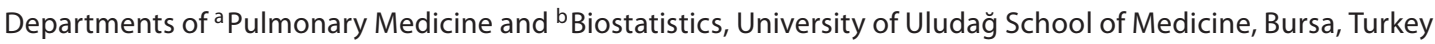

\section{Key Words}

Obesity · Preeclampsia • Pregnancy-induced hypertension • Snoring

\begin{abstract}
Background: Physical and hormonal changes during pregnancy alter breathing patterns of pregnant women. It is possible that occult disordered breathing during sleep may be a risk factor for the development of pregnancy-induced hypertension $(\mathrm{PIH})$ and preeclampsia. Objective: Our aim was to determine the incidence of self-reported snoring in pregnant women, and to investigate the relationship of snoring, obesity and neck circumference to PIH and preeclampsia. Methods: 469 pregnant women and 208 age-matched nonpregnant women were included in the study. Both groups were asked to complete a questionnaire. Maternal complications were retrieved from the medical records. Results: Habitual snoring was reported from $1.9 \%$ of nonpregnant women, $2.5 \%$ of pregnant women prior to pregnancy and $11.9 \%$ of those same women during the third trimester of pregnancy $(p<0.001)$. Age, smoking during pregnancy, and weight before delivery were independent risk factors for habitual snoring in pregnancy. PIH and preeclampsia developed in 20 and $10.9 \%$ of pregnant women with habitual snoring, as compared to 11 and $5.8 \%$ of non-snoring pregnant women ( $p=0.045, p=0.125, p=0.415)$, respectively. In women who developed preeclampsia, weight before preg-
\end{abstract}

nancy, weight before delivery and neck circumference were significantly higher in univariate analysis. Neck circumference was an independent risk factor for PIH and preeclampsia according to logistic regression analysis. Conclusion: The incidence of snoring is significantly higher in pregnant women than in nonpregnant women. Snoring may indicate a risk of PIH. Neck circumference was an independent risk factor for both PIH and preeclampsia.

Copyright $\odot 2007$ S. Karger AG, Basel

\section{Introduction}

Physical and hormonal changes during pregnancy alter breathing patterns of pregnant women. Some of these changes may provide protection from sleep-disordered breathing, while others may place women at increased risk $[1,2]$. The prevalence of self-reported snoring during pregnancy is $14 \%$ [3]. In Sweden, Franklin et al. [4] reported an incidence of $23 \%$ of regular snoring in 502 pregnancies, while only $4 \%$ of the same women reported snoring prior to pregnancy.

Snoring is an indicator of increased upper airway resistance and possible obstructive sleep apnea (OSA), which has been identified as an independent risk factor for the development of hypertension [5-7]. It is possible that occult disordered breathing during sleep may be a risk factor for the development of pregnancy-induced hy-

\section{KARGER}

Fax +4161306 1234 E-Mail karger@karger.ch www.karger.com
() 2007 S. Karger AG, Base 0025-7931/08/0761-0033\$24.50/0

Accessible online at:

www.karger.com/res
Ahmet Ursavas, MD

Uludağ Üniversitesi Tip Fakültesi

Gögüs Hastaliklari ve Tüberküloz AD

TR-16059 Görükle, Bursa (Turkey)

Tel. +90 2244428400 1730, Fax +90 224295 0939, E-Mail ahmetursavas@gmail.com 
pertension (PIH) and preeclampsia. Franklin et al. [4] found an association between snoring, maternal hypertension and preeclampsia. Furthermore, several studies suggested that the prevalence of habitual snoring in women was strongly dependent on body mass index (BMI) and neck circumference [8]. Neck circumference and BMI were strongest predictors of the severity of OSA [9]. Maternal obesity prior to pregnancy is a significant risk factor for adverse outcomes during pregnancy. The incidence of hypertensive disorders of pregnancy rises with increasing BMI [10].

The aim of our study was to determine the incidence of self-reported snoring in pregnant women, and to investigate the relationship among snoring, obesity, neck circumference, PIH and preeclampsia.

\section{Patients and Methods}

\section{Study Population}

We conducted the study at a large community hospital providing obstetric and gynecologic care in Bursa, Turkey. The ethics committee of the Uludag University, the Chief Physician of the maternity hospital and the Ministry of Health approved the study. A questionnaire was administered to pregnant women in the third trimester and age-matched nonpregnant healthy women from the general population. After completing an informed consent form, all participants were asked to complete a questionnaire. In both groups, women with a history of chronic hypertension, fetal mortality, multiple births, and cardiac, pulmonary and neuromuscular disease were excluded from the study.

\section{Questionnaire}

The questionnaire was administered by research assistants. When completing the questionnaire, the women were accompanied by their partners. Women were asked about insomnia, snoring and witnessed apnea, and these responses were graded on a Likert Scale of 0-4 [0 = never, $1=$ rarely (less than once a month), $2=$ sometimes (less than once a week), $3=$ often (at least once a week) and $4=$ always (almost every night)]. Habitual snoring was snoring that occurred often or always. Difficulty in falling asleep, frequent awakening with difficulty in falling asleep once again and early morning wakefulness were considered as insomnia symptoms. Pregnant women were asked to report their symptoms prior to pregnancy and during the third trimester.

The questionnaire also included the Epworth Sleepiness Scale (ESS), a 24-point scale that consists of eight situations requiring various degrees of vigilance, each with a score from 0 to 3 [11]. Age, medication, concomitant disease and smoking history were reported by the women. Height, weight, and neck circumference were measured by the research assistants.

\section{Maternal Complications}

Research assistants reviewed the medical records of the pregnant women. PIH was defined as repeated blood pressures of $140 / 90$ or greater appearing during pregnancy. Preeclampsia was defined as PIH with a 24 -hour urinary protein level $>0.3 \mathrm{~g}$.
Statistical Analysis

The data are presented as means \pm SD for continuous variables and as rates for nominal values. Student's t test for independent samples was used for normally distributed continuous variables. The Mann-Whitney U test was performed for non-normally distributed continuous variables. To assess the predictability of habitual snoring in pregnancy, we used a receiver-operating characteristic (ROC) curve, where the circumscribed area (the area under the curve) gives an estimate of the diagnostic efficiency of the test.

Odds ratios (OR) were computed using logistic regression. For multivariable analyses, binary logistic regression models were used. Statistical analysis was performed using the SPSS 13.0 software. A p value $<0.05$ was considered statistically significant.

\section{Results}

\section{Clinical Characteristics}

Seven hundred and twenty patients satisfied our inclusion criteria and were enrolled in our study. Forty-three patients were excluded because of incomplete questionnaire $(\mathrm{n}=10)$, chronic hypertension $(\mathrm{n}=6)$, multiple births $(n=5)$, and cardiac $(n=11)$, pulmonary $(n=10)$ and neuromuscular disease $(n=1)$. Four hundred and sixty-nine pregnant women (212 nulliparous and 257 multiparous) and 208 nonpregnant women completed the questionnaire. Mean age was $25.5 \pm 4.8$ years in pregnant women and $26.2 \pm 5.7$ years in nonpregnant women. Mean gestational age was $36.8 \pm 1.5$ weeks. None of the subjects had pulmonary or neuromuscular disease, or cancer.

In the pregnant group, 175 women or $37.3 \%$ were smokers prior to pregnancy and 76 or $14.5 \%$ reported smoking during their pregnancy. In the nonpregnant group, 76 or $36.5 \%$ were smokers. Prior to pregnancy, women reported a BMI of $22.8 \pm 3.8 \mathrm{~kg} / \mathrm{m}^{2}$, and in the nonpregnant group the BMI was $21.7 \pm 2.9 \mathrm{~kg} / \mathrm{m}^{2}$. Therefore, there was no significant difference in age $(\mathrm{p}=0.251)$, smoking $(\mathrm{p}=0.194)$ or BMI $(\mathrm{p}=0.102)$ between the two groups at baseline.

\section{Self-Reported Snoring}

Snoring frequencies were as follows: $77.9 \%$ never; $12.5 \%$ rarely; $7.7 \%$ sometimes; $0.5 \%$ often, and $1.4 \%$ always in the nonpregnant group; in the pregnant group, snoring frequencies were $77.1 \%$ never, $12.7 \%$ rarely, $7.6 \%$ sometimes, $1.2 \%$ often and $1.4 \%$ always prior to pregnancy, and $81.4 \%$ never, $2.6 \%$ rarely, $4.3 \%$ sometimes, $5.3 \%$ often and $6.4 \%$ always during the third trimester. Therefore, the reported frequency of habitual snoring was $1.9 \%$ in the nonpregnant group, and $2.5 \%$ prior to 
pregnancy and $11.7 \%$ during the third trimester in the pregnancy group. Habitual snoring was significantly more prevalent in the third trimester of pregnancy ( $\mathrm{p}<$ 0.001; fig. 1).

Habitual snoring in the third trimester correlated with mean age $(p=0.035)$, smoking during pregnancy $(p=$ $0.030)$, weight increase during pregnancy $(\mathrm{p}=0.025)$, weight before delivery $(\mathrm{p}=0.002)$ and neck circumference $(p=0.004)$. There were no significant differences

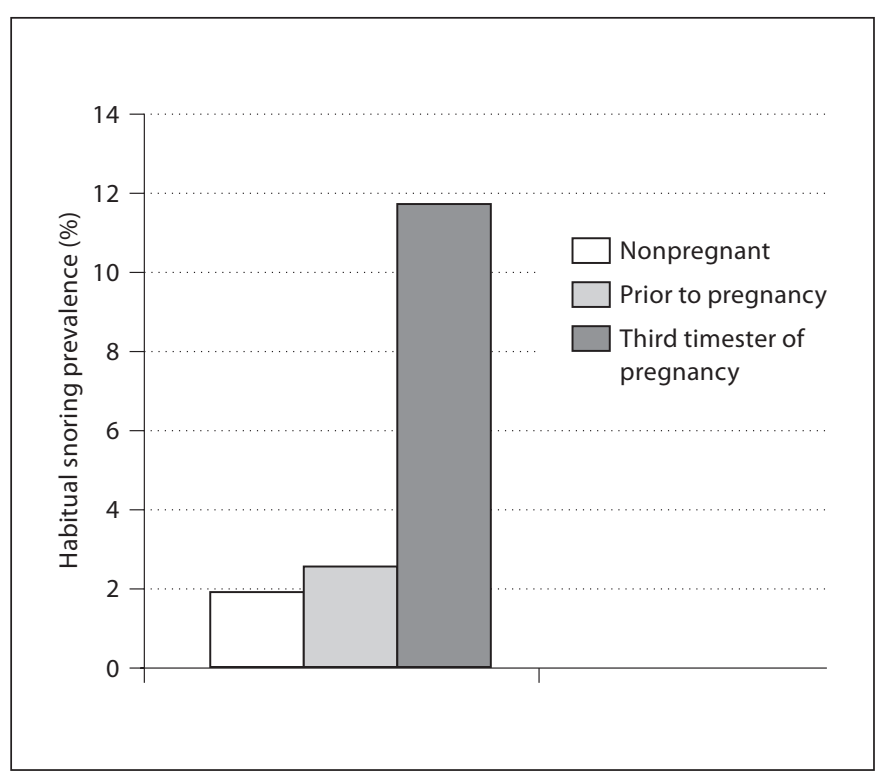

Fig. 1. Habitual snoring prevalence. regarding smoking, BMI or weight prior to pregnancy between the habitual and nonhabitual snoring pregnant women (table 1).

We used ROC analysis with significantly different parameters between habitual and nonhabitual snorers in univariate analysis. We determined that age, weight before delivery, weight increase during pregnancy and neck circumference were the most useful predictors of habitual snoring. Multivariate analysis was applied for significantly different parameters between habitual and nonhabitual snorers in univariate analysis. The results of multivariate analysis including age, smoking during pregnancy, weight before delivery, weight increase during pregnancy and neck circumference are summarized table 2. Age (OR: 2.03, 95\% confidence interval, CI: $1.09-$ $3.76, \mathrm{p}=0.024)$, smoking during pregnancy (OR: 2.93, 95\% CI: $1.20-7.16, \mathrm{p}=0.014$ ) and weight before delivery (OR: $2.12,95 \%$ CI: $0.99-4.53, \mathrm{p}=0.049$ ) were independent risk factors for habitual snoring in pregnancy according to binary logistic regression analysis.

\section{Insomnia, Excessive Daytime Sleepiness, \\ Witnessed Apnea}

Prior to pregnancy, insomnia and witnessed apnea were reported by 2.4 and $0.85 \%$, respectively, versus 49.3 and $9.1 \%$ during the third trimester of pregnancy, respectively. The prevalence of insomnia was significantly higher in the third trimester of pregnancy. Insomnia in pregnancy was similar between habitual snorers and those who were not, but ESS ( $\mathrm{p}=0.034$ ) was significantly higher in habitual snorers.
Table 1. Habitual and nonhabitual snorers in pregnancy

\begin{tabular}{llcc}
\hline Characteristics & $\begin{array}{l}\text { Habitual } \\
\text { snorers }\end{array}$ & $\begin{array}{l}\text { Nonhabitual } \\
\text { snorers }\end{array}$ & p value \\
\hline Age, years & $26.7 \pm 5.1$ & $25.3 \pm 4.8$ & 0.035 \\
Smoking before pregnancy $(\mathrm{n}=175), \%$ & 47.3 & 36 & 0.071 \\
Smoking during pregnancy $(\mathrm{n}=68), \%$ & 27.3 & 12.8 & 0.030 \\
BMI before pregnancy, kg/m ${ }^{2}$ & $23.6 \pm 4.1$ & $22.8 \pm 3.8$ & 0.226 \\
Weight before pregnancy, kg & $61.1 \pm 10.4$ & $57.8 \pm 9.8$ & 0.136 \\
Weight increase during pregnancy, kg & $13.9 \pm 5.7$ & $12.1 \pm 5.4$ & 0.025 \\
Weight before delivery, kg & $75.2 \pm 11.7$ & $70.7 \pm 10.2$ & 0.002 \\
Neck circumference before delivery, cm & $34.5 \pm 2.4$ & $33.7 \pm 2.0$ & 0.004 \\
ESS & $7.3 \pm 2.6$ & $4.56 \pm 2.1$ & 0.034 \\
PIH (n = 57), \% & 20 & 11.1 & 0.045 \\
Preeclampsia (n = 30), \% & 10.9 & 5.8 & 0.125 \\
Systolic blood pressure, mm Hg & $117.3 \pm 15.8$ & $115.5 \pm 25.1$ & 0.862 \\
Diastolic blood pressure, mm Hg & $72.4 \pm 10.6$ & $71.2 \pm 11.1$ & 0.482 \\
Nullipara/multipara & $22 / 33$ & $190 / 224$ & 0.128 \\
\hline
\end{tabular}




\section{PIH and Preeclampsia}

Thirty (6.4\%) pregnant women met the definition of preeclampsia with hypertension and proteinuria. Preeclampsia was observed in $10.9 \%$ of habitual snorers versus $5.8 \%$ of nonhabitual snorers $(\mathrm{p}=0.125)$. Fifty-seven (12.2\%) pregnant women met the definition of PIH. PIH was observed in $20 \%$ of habitual snorers and $11.1 \%$ of nonhabitual snorers $(\mathrm{p}=0.045)$. Twenty percent of women with preeclampsia and $19.3 \%$ of women with PIH had habitual snoring during the third trimester of pregnancy.

In pregnant women who had PIH, snoring $(\mathrm{p}=0.05)$, weight before pregnancy $(\mathrm{p}<0.001)$, weight before delivery $(\mathrm{p}<0.001)$ and neck circumference $(\mathrm{p}<0.001)$ were

Table 2. Risk factors of snoring in pregnancy in multivariate analysis

\begin{tabular}{|c|c|c|c|}
\hline Variables & OR & $95 \%$ CI & $\mathrm{p}$ value \\
\hline \multicolumn{4}{|l|}{ Age } \\
\hline$\leq 26$ years & 1.000 & \multirow[t]{2}{*}{$1.095-3.756$} & \multirow[t]{2}{*}{0.024} \\
\hline$>26$ years & 2.028 & & \\
\hline \multicolumn{4}{|c|}{ Smoking during pregnancy } \\
\hline No & 1.000 & \multirow[t]{2}{*}{$1.202-7.161$} & \multirow[t]{2}{*}{0.014} \\
\hline Yes & 2.934 & & \\
\hline \multicolumn{4}{|c|}{ Weight before delivery } \\
\hline$\leq 69 \mathrm{~kg}$ & 1.000 & \multirow[t]{2}{*}{$0.997-4.538$} & \multirow[t]{2}{*}{0.049} \\
\hline$>69 \mathrm{~kg}$ & 2.127 & & \\
\hline \multicolumn{4}{|c|}{ Weight increase during pregnancy } \\
\hline$\leq 9.5 \mathrm{~kg}$ & 1.000 & \multirow[t]{2}{*}{$0.764-3.768$} & \multirow[t]{2}{*}{0.194} \\
\hline$>9.5 \mathrm{~kg}$ & 1.696 & & \\
\hline \multicolumn{4}{|c|}{ Neck circumference before delivery } \\
\hline$\leq 34.7 \mathrm{~cm}$ & 1.000 & \multirow[t]{2}{*}{$0.914-3.180$} & \multirow[t]{2}{*}{0.093} \\
\hline$>34.7 \mathrm{~cm}$ & 1.705 & & \\
\hline
\end{tabular}

significantly higher than in normotensive pregnant women. In preeclamptic women, weight before pregnancy $(p<0.001)$, weight before delivery $(p<0.001)$ and neck circumference $(\mathrm{p}<0.001)$ were significantly higher (table 3).

We used ROC analysis with significantly different parameters between hypertensive and normotensive pregnant women in univariate analysis. We determined that weight before pregnancy, weight before delivery and neck circumference are the most useful values predicting PIH and preeclampsia. The result of multivariate analysis including habitual snoring, weight before pregnancy, weight before delivery and neck circumference are summarized in table 4 . Neck circumference was an independent risk factor for PIH and preeclampsia using binary logistic regression analysis.

\section{Discussion}

Among the many physiologic changes during pregnancy are alterations in upper airway and respiratory function, and in sleep. Habitual snoring is increased during pregnancy. Possible mechanisms leading to increased upper airway resistance are pharyngeal edema and weight gain. Also, nasal congestion and rhinitis are common during pregnancy due to elevated estrogen levels. These factors increase snoring and upper airway obstruction $[12,13]$.

Previous studies have reported increases in snoring during pregnancy. Loube et al. [3] noted habitual snoring in $14 \%$ of pregnant women, which was significantly increased compared with age-matched nonpregnant women. In a similar study carried out by Franklin et al. [4] in Sweden, 502 pregnant women were asked to complete a

Table 3. Risk factors of PIH and preeclampsia in pregnant women

\begin{tabular}{|c|c|c|c|c|c|c|}
\hline \multirow[t]{2}{*}{ Characteristics } & \multicolumn{3}{|l|}{$\mathrm{PIH}$} & \multicolumn{3}{|l|}{ Preeclampsia } \\
\hline & yes $(n=57)$ & no $(n=412)$ & $\mathrm{p}$ value & yes $(n=30)$ & no $(n=439)$ & $\mathrm{p}$ value \\
\hline Age, years & $26.9 \pm 6.1$ & $25.3 \pm 4.6$ & 0.151 & $27.3 \pm 6.5$ & $25.4 \pm 4.7$ & 0.209 \\
\hline Habitual snoring, \% & 19.3 & 10.7 & 0.050 & 20 & 11.2 & 0.145 \\
\hline Smoking, \% & 28.1 & 38.6 & 0.800 & 20 & 38.5 & 0.071 \\
\hline Smoking, pack/years & $1.16 \pm 3.74$ & $1.05 \pm 2.59$ & 0.610 & $1.05 \pm 3.9$ & $1.06 \pm 2.6$ & 0.061 \\
\hline Neck circumference, $\mathrm{cm}$ & $35.1 \pm 2.21$ & $33.6 \pm 2.01$ & $<0.001$ & $35.4 \pm 2.21$ & $33.7 \pm 2.0$ & $<0.001$ \\
\hline Weight before pregnancy, kg & $64.8 \pm 11.8$ & $58.2 \pm 9.3$ & $<0.001$ & $66.2 \pm 12.3$ & $58.5 \pm 9.5$ & $<0.001$ \\
\hline Weight increase during pregnancy, kg & $12.6 \pm 4.9$ & $12.3 \pm 5.4$ & 0.420 & $12.5 \pm 4.5$ & $12.3 \pm 5.1$ & 0.420 \\
\hline Weight before delivery, kg & $76.8 \pm 10.8$ & $70.4 \pm 10.1$ & $<0.001$ & $78.7 \pm 10.5$ & $70.7 \pm 10$ & $<0.001$ \\
\hline
\end{tabular}


Table 4. Risk factors of PIH and preeclampsia in pregnant women in multivariate analysis

\begin{tabular}{|c|c|c|c|c|c|c|}
\hline \multirow[t]{2}{*}{ Variables } & \multicolumn{3}{|l|}{$\mathrm{PIH}$} & \multicolumn{3}{|c|}{ Preeclampsia } \\
\hline & OR & $95 \% \mathrm{CI}$ & $\mathrm{p}$ value & OR & $95 \% \mathrm{CI}$ & $\mathrm{p}$ value \\
\hline \multicolumn{7}{|c|}{ Habitual snoring } \\
\hline $\begin{array}{l}\text { No } \\
\text { Yes }\end{array}$ & 1.59 & $0.74-3.42$ & 0.232 & 1.49 & $0.55-4.05$ & 0.426 \\
\hline $\begin{array}{l}\text { Weight befor } \\
\leq 62.5 \mathrm{~kg} \\
>62.5 \mathrm{~kg}\end{array}$ & 1.31 & $0.59-2.87$ & 0.502 & 1.65 & $0.56-4.83$ & 0.360 \\
\hline $\begin{array}{l}\text { Weight befor } \\
\leq 77 \mathrm{~kg} \\
>77 \mathrm{~kg}\end{array}$ & 1.65 & $0.74-5.37$ & 0.215 & 2.08 & $0.72-5.98$ & 0.173 \\
\hline $\begin{array}{r}\text { Neck circumf } \\
\leq 34.7 \mathrm{~cm} \\
>34.7 \mathrm{~cm}\end{array}$ & 2.85 & $1.51-5.37$ & 0.001 & 3.57 & $1.43-8.88$ & 0.006 \\
\hline
\end{tabular}

questionnaire. They found that during the last week of pregnancy, $23 \%$ of the women reported snoring every night. Only $4 \%$ reported snoring before their pregnancy. The increase in the incidence of snoring during pregnancy suggests a probable correlation with sleep-disordered breathing. However, actual prevalence of sleep-disordered breathing during pregnancy is unknown. Guilleminault et al. [14] investigated 267 pregnant women in a two-stage study. All subjects underwent ambulatory monitoring of their sleep with a 6-channel recorder at the 6 -month prenatal visit. Snoring prevalence was 3.7\% prior to pregnancy and $11.8 \%$ during the last trimester. In the second stage of the study, 26 subjects underwent polysomnography, 13 based on symptoms, blood pressure values and the ambulatory monitoring results and 13 chosen at random from the group. Abnormal respiratory patterns were detected, but none of the subjects were established to have apnea or hypopnea. Edwards et al. [15] performed overnight polysomnography and continuous systemic blood pressure monitoring during the third trimester of pregnancy and 3 months following delivery. They reported that an improvement in both the apneahypopnea index and minimum arterial oxyhemoglobin saturation occurred consistently in all subjects postnatally. In our study, habitual snoring was found in $11.7 \%$ of pregnant women during the third trimester of pregnancy, while only $2.5 \%$ of them reported snoring prior to pregnancy and $1.90 \%$ of our nonpregnant group reported habitual snoring.

Age, obesity and smoking predispose to snoring and other sleep-related breathing disorders. The prevalence of habitual snoring in middle-aged French males was reported to be $32 \%$. Age, neck circumference, tobacco con- sumption, weight excess and large soft palate were independently associated with snoring [16]. Resta et al. [17] investigated the prevalence of snoring and OSA in obese subjects. They showed that neck circumference in men and BMI in women were strongest predictors of the severity of OSA. Maasilta et al. [18] recruited 11 obese and 11 control women. Overnight polysomnography was performed in early and late pregnancy. They showed that early and late pregnancy apnea-hypopnea indexes, oxygen desaturation, arousal indexes and snoring times were significantly higher in the obese pregnant women as compared to the nonobese pregnant controls. The results of our study also indicate that age, smoking during pregnancy and weight before delivery were independent risk factors for habitual snoring in pregnancy in logistic regression analysis. Furthermore, neck circumference is higher in habitual snorers compared with nonhabitual snorers in univariate analysis.

Most pregnant women report alterations in sleep. During the third trimester, total sleep time decreases, while insomnia, nocturnal awakening and daytime sleepiness increase [19]. The most common reasons given for third trimester sleep disturbances are fetal movement, backache, general abdominal discomfort, urinary frequency, heartburn and leg cramps [20]. A prospective study of 33 pregnant women noted an increase in total sleep time in the first trimester, normalization by in the second trimester and a decrease in the third trimester [21]. Franklin et al. [4] found that daytime sleepiness started during the first trimester in $25 \%$ of the women, during the second trimester in $18 \%$ and during the third trimester in $22 \%$. They did not find a difference in daytime sleepiness between habitual snorers and nonhabitu- 
al snorers. Loube et al. [3] also could not find a relationship between daytime sleepiness and snoring in pregnant women using ESS. Izci et al. [22] investigated 167 healthy pregnant women, 82 women with preeclampsia and 160 non-pregnant women. They reported $32 \%$ of control, $55 \%$ of pregnant and $85 \%$ of women with preeclampsia snored. In this study, $53.1 \%$ of pregnant women had self-reported daytime sleepiness during the third trimester. In pregnancy, ESS were significantly higher in habitual snorers.

Preeclampsia is a multisystem disorder observed in 7-9\% of pregnant women. Nocturnal blood pressure values are higher compared with daytime values in preeclampsia, and diurnal variations occur [23]. Snoring during pregnancy may be an important finding as it has been associated with PIH and preeclampsia. Gislason et al. [6] demonstrated a strong correlation between hypertension and snoring in pregnancy. Izci et al. [24] compared upper airway dimensions in pregnant and nonpregnant women and in patients with preeclampsia. They showed that women with preeclampsia have upper airway narrowing both upright and supine. They suggested that these changes could contribute to the upper airway resistance episodes during sleep in patients with preeclampsia, which may further increase their blood pressure. Edwards et al. [25] hypothesized that snoring and partial upper airway obstruction contribute to nocturnal rises in blood pressure. They tested this hypothesis by controlling sleep-induced upper airway flow limitation and snoring with nasal positive pressure. They demonstrated that partial upper airway obstruction is associated with increments in blood pressure during sleep in women with preeclampsia, which can be treated with nasal continuous positive airway pressure. Franklin et al. [4] indicated that PIH and preeclampsia were significantly higher in snoring than nonsnoring pregnant women. In a recent study, the prevalence of PIH was found to be $4.5 \%$, and correlated with BMI as well as snoring and decreased vigilance measured with a standard scale [26]. In our study, although PIH was significantly higher in snorers compared to nonsnorers, preeclampsia was not shown to be significantly different between snorers and nonsnorers. There are two reasons for this result. First, our subjects (both pregnant and nonpregnant ones) were younger than those of other studies. Second, our preeclamptic sample size was limited.

Risk factors for preeclampsia and PIH include sociodemographic factors (age, socioeconomic status and ethnic group), genetic factors, pregnancy factors (nulliparity and previous preeclampsia) or personal history (obesity, chronic renal disease, chronic hypertension, di- abetes mellitus and thrombophilia) [27]. Robinson et al. [28] investigated 142,404 singleton pregnancies. They found that obesity increased the risk of PIH. Neck circumference, a simple and time-saving screening measure to identify obesity, is reported to be positively correlated with the factors of the metabolic syndrome: obesity; insulin resistance; hyperlipidemia; hypertension, and coronary heart disease [29]. Ben-Noun et al. [30] showed that higher neck circumference positively correlated with systolic and diastolic blood pressures in 364 healthy subjects. Age, neck circumference and BMI were the strongest predictors of an elevated apnea-hypopnea index [31, 32]. Neck circumference increases during pregnancy due to weight gain. Pien et al. [33] demonstrated that women with higher baseline BMI and greater increases in neck circumference during pregnancy reported higher apnea symptom scores. In our study, neck circumference was an independent risk factor for PIH and preeclampsia in to logistic regression analysis. Weight gain in pregnancy may cause higher neck circumference, habitual snoring and higher prevalence of PIH in obese women. The increased prevalence of PIH in women with increased neck circumference could be related to the frequency of apnea.

Potential limitations of this study merit consideration. The pregnancy group was asked to report retrospectively on weight and snoring prior to pregnancy. Reporting on snoring is subjective, although it was supported by their partners. There is no particular study which evaluated the reliability and validity of ESS in pregnant women. These same problems exist in similar studies, too. Finally, we used ROC curves to generate cutoffs to define predictors for snoring. Subsequently, these variables were applied in multivariate analysis. This approach of datadriven strategy might have affected the results of our study.

In conclusion, habitual snoring was significantly more prevalent in the third trimester of pregnancy. Age, smoking during pregnancy and weight before delivery were independent risk factors for habitual snoring in pregnancy. The prevalence of excessive daytime sleepiness and insomnia were significantly higher in the third trimester. In women with preeclampsia, weight before pregnancy, weight before delivery and neck circumference were significantly increased in comparison to women without preeclampsia. Neck circumference was an independent risk factor for $\mathrm{PIH}$ and preeclampsia in logistic regression analysis. 


\section{References}

-1 Feinsilver SH, Hertz G: Respiration during sleep in pregnancy. Clin Chest Med 1992;13: 637-644.

2 Kowall J, Clark G, Nino-Murcia G, et al: Precipitation of obstructive sleep apnea during pregnancy. Obstet Gynecol 1989;74:453455.

-3 Loube MD, Poceta S, Morales MC, et al: Selfreported snoring in pregnancy: Association with fetal outcome. Chest 1996;109:885889.

4 Franklin KA, Holingren PA, Jönsson F, et al: Snoring, pregnancy-induced hypertension, and growth retardation of the fetus. Chest 2000;117:137-141.

5 Tryfon S, Stanopoulos I, Dascalopoulou E, et al: Sleep apnea syndrome and diastolic blood pressure elevation during exercise. Respiration 2004;71:499-504.

6 Gislason T, Benediktsdottir B, Björnsson JK, et al: Snoring, hypertension and the sleep apnea syndrome. An epidemiologic survey of middle aged woman. Chest 1993;103:11471151.

7 Peker Y, Hedner J, Norum J, et al: Increased incidence of cardiovascular disease in middle-aged men with obstructive sleep apnea: a 7-year follow-up. Am J Respir Crit Care Med 2002;166:159-165.

$>8$ Svensson M, Lindberg E, Naessen T, et al: Risk factors associated with snoring in women with special emphasis on body mass index: a population-based study. Chest 2006; 129:933-941.

-9 Van Kralingen KW, de Kanter W, de Groot $\mathrm{GH}$, et al: Assessment of sleep complaints and sleep-disordered breathing in a consecutive series of obese patients. Respiration 1999;66:312-316.

10 Bodnar LM, Catov JM, Klebanoff MA, et al: Prepregnancy body mass index and the occurrence of severe hypertensive disorders of pregnancy. Epidemiology 2007;18:234-239.

$\checkmark 11$ Johns MW: A new method for measuring daytime sleepiness: the Epworth sleepiness scale. Sleep 1991;14:540-545.
12 Pilkington S, Carli F, Dakin MJ, et al: Increase in Mallampati score during pregnancy. Br J Anaesth 1995;74:638-642.

13 Stubner UP, Gruber D, Berger UE, et al: The influence of female sex hormones on nasal reactivity in seasonal allergic rhinitis. Allergy 1999;54:865-871.

14 Guilleminault C, Querra-Salva M, Chowdhuri S, et al: Normal pregnancy, daytime sleeping, snoring and blood pressure. Sleep Med 2000;1:289-297.

15 Edwards N, Blyton DM, Hennessy A, et al: Severity of sleep-disordered breathing improves following parturition. Sleep 2005;28: 737-741

16 Teculescu D, Hannhart B, Cornette A, et al: Prevalence of habitual snoring in a sample of French males. Role of 'minor' nose-throat abnormalities. Respiration 2001;68:365370.

17 Resta O, Foschino-Barbora MP, Legari G, et al: Sleep related breathing disorders, loud snoring and excessive daytime sleepiness in obese subjects. Int J Obes Relat Metab Disord 2001;25:669-675.

18 Maasilta P, Bachour A, Teramo K, et al: Sleep-related disordered breathing during pregnancy in obese women. Chest 2001;120: 1448-1454.

19 Karacan I, Wayne H, Harman AW, et al: Characteristics of sleep pattern during late pregnancy and the postpartum periods. Am J Obstet Gynecol 1968;101:579-586.

20 Suzuki S, Dennerstein L, Greenwood KM, et al: Sleeping patterns during pregnancy in Japanese women. J Psychosom Obstet Gynecol 1994;15:19-26.

21 Lee KA, Zaffke ME, McEnany G: Parity and sleep patterns during and after pregnancy. Obstet Gynecol 2000;95:14-18.

22 İzci B, Martin SE, Dundas KC, et al: Sleep complaints: snoring and daytime sleepiness in pregnant and preeclamptic women. Sleep Med 2005;6:163-169.

23 Beilin LJ, Deacon J, Michael CA, et al: Diurnal rhythms of blood pressure, plasma renin activity, angiotensin II and catecholamines in normotensive and hypertensive pregnancies. Clin Exp Hypertens 1983;B2:271-293.
24 İzci B, Riha RL, Martin SE, et al: The upper airway in pregnancy and pre-eclampsia. Am J Respir Crit Care Med 2003;167:137-140.

25 Edwards N, Blyton DM, Kirjavainen T, et al: Nasal continuous positive airway pressure reduces sleep-induced blood pressure increments in preeclampsia. Am J Respir Crit Care Med 2000;162:252-257.

$\checkmark 26$ Calaora-Tournadre D, Ragot S, Meurice JC, et al: Obstructive sleep apnea syndrome during pregnancy: prevalence of main symptoms and relationship with pregnancy-induced hypertension and intrauterine growth retardation (in French). Rev Med Interne 2006;27:291-295.

27 Smith RA, Baker PN: Risk factors, prevention and treatment of hypertension in pregnancy. Minerva Ginecol 2005;57:379-388.

28 Robinson HE, O'Connell CM, Joseph KS, et al: Maternal outcome in pregnancies complicated by obesity. Obstet Gynecol 2005;106: 1357-1364.

29 Fink B, Manning JT, Neave N: The 2nd-4th digit ratio (2D:4D) and neck circumference: implications for risk factors in coronary heart disease. Int J Obes (Lond) 2005;30:711714.

30 Ben-Noun L, Sohar E, Laor A: Neck circumference as a simple screening measure for identifying overweight and obesity patients. Obes Res 2001;9:470-474.

31 Resta O, Bonfitto P, Sabato R, et al: Prevalence of obstructive sleep apnoea in a sample of obese women: effect of menopause. Diabetes Nutr Metab 2004;17:296-303.

$>32$ Hora F, Napolis LM, Daltro C, et al: Clinical, anthropometric and upper airway anatomic characteristics of obese patients with obstructive sleep apnea syndrome. Respiration 2007;74:517-524.

33 Pien GW, Fife D, Pack AI, et al: Changes in symptoms of sleep-disordered breathing during pregnancy. Sleep 2005;28:12991305. 